\title{
An Analysis of the Equal Opportunity of Graduate Students in China's First-class Universities Based on the Enrollment Policy
}

\author{
Xueqian Zhang ${ }^{1 *} \quad$ Jinlong $\mathrm{Li}^{2}$ \\ 1.School of Public Affairs, University of Science and Technology of China, \\ 96 Jin Zhai Road, Hefei 230000, Anhui Province, China \\ 2.School of Graduate, University of Science and Technology of China, \\ 96 Jin Zhai Road, Hefei 230000,Anhui Province, China
}

\begin{abstract}
Based on the theory of social justice in New Ethics and Rawls's theory of justice, this paper discussed the connotation of equal opportunity for postgraduate entrance in china. Taking China's 42 first-class universities as an example, the practice level of equal opportunity was evaluated in postgraduate entrance, from two dimensions, including academic degree postgraduate and professional degree postgraduate, through constructed the opportunity inequality index. Based on the two kinds of causes and three concrete manifestations of unequal opportunities, the quantitative analysis is carried out through the introduction of the unequal contribution degree. In the end, some suggestions are put forward to promote the equal opportunity of postgraduate entrance, such as "reducing discriminatory conditions of applicants, opening enrollment requirements", "increasing the number of univesities that have the candidates who exempted from unified-examination, and setting up reasonable enrollment plan of this type candidates".
\end{abstract}

Keywords: postgraduate enrollment policy, equal opportunity, first-class university

DOI: $10.7176 / \mathrm{PPAR} / 9-3-04$

Publication date:March $31^{\text {st }} 2019$

\section{Introduction}

According to the source, opportunities can be divided into opportunities provided by society and non-social opportunities, social opportunities consist of basic rights opportunities and non-basic rights opportunities, nonsocial opportunities include opportunities provided by nature and unnatural opportunities (Wang Haiming, 2001). Principle of opportunity holding, ( i ) non-basic rights opportunities provided by the society belongs to the public right, which are basic human rights and follow the principle of complete equality (Wang Haiming,2001), and (ii) non-social opportunities are individual rights, which followed the principle of equal liberty and the principle of compensation(Rawls, 1999).

Equality is the sameness between people in terms of gaining benefits (Wang Haiming, 2001). Equality can be divided into natural equality and man-made equality, natural equality has nothing to do with morality; the essence of man-made equality is equality of rights, and it includes the equality of basic rights and the equality of non-basic rights. The principle of equality, ( $\mathrm{i}$ ) natural equality does not belong to the category of rights, and it follows the principle of complete equality, and (ii) man-made equality includes the principle of complete equality of basic rights, the principle of equal proportion of non-basic rights and the principle of compensation (Wang Haiming, 2001).

Equal opportunity is essentially equality of rights, its principle is a system of principle, which is composed of the principle of opportunity holding and the principle of equality, including the principle of two levels, ( i ) basic principle, such as the principle of opportunity holding and the principle of equality, ( ii) the principle of implementation of the basic principles, the basic principles have different priorities, the "lexical sequence" is the principle of complete equality, the principle of equal liberty, the principle of proportionality and the principle of compensation, the latter principle can be satisfied only if the former principle is satisfied (Wang Haiming, 2001; Rawls, 2001). The practice of equal opportunity is inconsistent with its principle system, which causes inequality of opportunity.

\section{Theoretical basis}

2.1 The definition of equal opportunities for postgraduate entrance

Postgraduate education is an important part of the education system, and it is still provided by the society in China. Therefore, postgraduate education opportunities fall into the category of basic rights, and its holding is based on the principle of complete equality. Because of the human diversity, which involves both natural and man-made equality, equal opportunity of postgraduate education is natural equality and man-made equality in opportunity provided by the society (Sen A, 2016), the principle is as follows, the principle of complete equality of value order; the principle of proportionality, and the principle of compensation.

Therefore, this article defines the equal opportunity of postgraduate entrance as follows: all the favorable 
conditions provided by society, such as the enrollment plan and resource allocation for postgraduate enrollment, should first of all be completely opened up to all candidates who meet the requirements of the state regulations, then allocate resources proportionately, and finally, the disadvantaged people should be given some compensation because superior people make more use of public resources for education. Just as Rawls' two principles of justice: first, each person is to have an equal right to the most extensive scheme of equal basic liberties compatible with a similar scheme of liberties for others. Second, social and economic inequalities are to be arranged so that they are both (a) reasonably expected to be to everyone's advantage, and (b) attached to positions and offices open to all (Rawls, 1999; Rawls, 2001).

\subsection{The evaluation dimension of equal opportunities for postgraduate entrance}

The postgraduate are divided into academic degree and professional degree according to degree type in China.Therefore, this paper evaluates the equal opportunity of postgraduate in China from the two dimensions of degree type, postgraduate enrollment for academic degree and professional degree.

\section{Methodology}

\subsection{Research design}

Above the equal opportunity of entrance is a broad definition, due to the availability of data in practical research, especially pointed out here below the focus and limitations of the practical research on equal opportunity. It mainly focuses on the unequal opportunity caused by the violation of the principle of complete equality, that is, the lack of opportunities. This article also does not study the inequalities caused by the principle of equal proportionality and the principle of compensation.

The enrollment institutions should publish the general regulation of enrollment, including the enrollment catalogue, the specific plan of enrollment and so on (MOE 2017). In addition, all disciplines must set aside a certain percentage of enrollment plan for recruiting candidates for the national unified examination (MOE 2017; MOE 2013).

According to the above policy requirements and the actual situation of enrollment institutions, enrollment disciplines can be divided into three categories (six sub-categories), ( i )completely open to all candidates, enrollment information completely open, this type of enrollment discipline is represented by " $\mathrm{N}_{1}$ ", ( ii) completely open to all candidates, but enrollment information is not completely open, including the enrollment plan of specific discipline is not open, the enrollment plan of candidates exempt from unified-examination is not open, these two disciplines are represented respectively by $\mathrm{N}_{2}$ and $\mathrm{N}_{3}$, and(iii) not fully open to all candidates, enrollment institutions to add other conditions and requirements for admission, that is, enrollment is only open to the those candidates, including the candidates who exempted from unified-examination(represented in $\mathrm{N}_{4}$ ), the candidates are required to have a bachelor's degree(represented in $\mathrm{N}_{5}$ ); those candidates who is equivalent students, college to undergraduate, graduates from independent colleges and private colleges, are not allowed to apply for a postgraduate examination, this type of enrollment discipline is represented by "N6". According to the above definition of equal opportunity, if the general regulation of enrollment is not completely open to all the candidates who meet the national requirements, it will result in unequal opportunities. The latter three types of discipline are the concrete manifestation of the unequal opportunity, the level of inequality is set out as follows.

\subsection{Research approach}

Measurement of unequal opportunity:

( i ) the statistical standard of the six category of discipline(Babbie E R, 2007),

$$
\mathrm{U}=\bigcup_{i=1}^{6} N_{i} \quad \emptyset=N_{i} \cap N_{j}
$$

(i, $\mathrm{j}=1,2,3,4,5,6 ; \mathrm{i} \neq \mathrm{j})$, statistical priority, $\mathrm{N}_{1} \cup\left[\left(\mathrm{N}_{4} \cup \mathrm{N}_{5} \cup \mathrm{N}_{6}\right)>\mathrm{N}_{2}>\mathrm{N}_{3}\right]$.

(ii ) Opportunity Inequality Index(Sen A, 2016; Sen A, 1976; Gini C, 1912),

$$
\begin{aligned}
& \mathrm{O}=H \cdot[I+(1-I) \cdot G] \\
& \mathrm{H}=q / n \\
& \mathrm{q}=\sum_{i=4}^{3} n_{i} \\
& \mathrm{n}=\sum_{i=1}^{6} n_{i} \\
& \mathrm{I}=\sum_{i=4}^{3}\left(Z-Y_{i}\right) \cdot n_{i} / Z q
\end{aligned}
$$


$\mathrm{G}=\sum_{i=1}^{6} X_{i} \cdot W_{i}+2 \sum_{i=1}^{6} X_{i} \cdot\left(1-V_{i}\right)-1$

$X_{i}=n_{i} / n$

$W_{i}=Y_{i} \cdot n_{i} / \sum_{i=1}^{6} Y_{i} \cdot n_{i}$

$V_{i}=\sum W_{i}$

$\mathrm{H}$ represents the ratio of unequal discipline,ni represents the number of disciplines i; I is the equal gap ratio, $\mathrm{Y}$ represents the equal value of unequal disciplines, $\mathrm{Z}$ is equal line, $\mathrm{G}$ is the Gini coefficient for all disciplines, $\mathrm{Xi}$ represents the proportion of discipline $\mathrm{i}$,Wi represents the proportion of equal value of the discipline $\mathrm{i}, \mathrm{Vi}$ is the cumulative proportion of equal value of discipline $\mathrm{i}$.

(iii) the equal value of the enrolment discipline, it is assumed that the scope of the equal value for discipline is $[0$, 1], 0 represent complete inequality, 1 represent complete equality, 0.5 is the unequal line, therefore, $\mathrm{Y} 1=\mathrm{Y} 2=\mathrm{Y} 3=1$ (Babbie E R, 2007); the causes of inequality can be divided into biases and discrimination, bias refers to the fact that the enrollment plan is only open to advantage candidate and leads to a lack of opportunities for other candidates, discrimination means that some candidates have been deprived of the opportunity for examination, according to social origin(Nagel T, 1995), therefore, the ratio of the degree of inequality among Y4, Y5 and Y6 is $0.5: 0.5: 1$, the equal value is $0.25,0.25,0$ respectively(Babbie E R, 2007).

(iv) The range of opportunity inequality index, 0 means that the distribution of opportunities is completely equal and 1 means complete inequality.

Measurement of the degree of unequal contribution for enrollment dicipiline,

$$
C_{i}=\left(Z-Y_{i}\right) \cdot n_{i} / \sum_{i=4}^{3}\left(Z-Y_{i}\right) \cdot n_{i}
$$

the degree of inequality of dicipline $i$ accounts for the proportion of all disciplines.

\subsection{Samples}

The sample is forty-two building first-class universities in China, the data are from the postgraduate enrolment documents of the universities in 2018. The research objects includes the candidates who exempted from unifiedexamination, and the national examination, not including military graduate students, special programs(the military plan, minority plan, tibet plan), individual enrollment examination, foreign and Hong Kong and Macao candidates.

According to the research method above, the opportunity inequality index of entance in 42 universities is like table 1, from the two dimensions of degree type, postgraduate enrollment for academic degree and professional degree. 
Table 1. Opportunity Inequality Index of 42 Universitis in Two Dimension

\begin{tabular}{|l|l|l|l|l|l|}
\hline University & academic degree professional degree & Universitylacademic degree & professional degree \\
\hline 1 & 0.111 & 0.033 & 21 & 0.248 & 0.272 \\
\hline 2 & 0.011 & 0.020 & 22 & 0.034 & 0.175 \\
\hline 4 & 0.013 & 0 & 23 & 0.030 & 0.065 \\
\hline 5 & 0.014 & 0 & 24 & 1.000 & 0.830 \\
\hline 6 & 0 & 0 & 25 & 0 & 0 \\
\hline 7 & 0.053 & 0.017 & 26 & 0.391 & 0.429 \\
\hline 8 & 0.044 & 0 & 27 & 1.000 & 0.971 \\
\hline 9 & 0.089 & 0.045 & 28 & 1.000 & 1.000 \\
\hline 10 & 0 & 0 & 29 & 0.005 & 0.012 \\
\hline 11 & 0 & 0 & 30 & 0.037 & 0.038 \\
\hline 12 & 0.008 & 0 & 31 & 0 & 0.036 \\
\hline 13 & 0.004 & 0.892 & 32 & 0 & 0 \\
\hline 14 & 0.076 & 0.031 & 33 & 0 & 0 \\
\hline 15 & 1.000 & 0.978 & 34 & 0 & 0 \\
\hline 16 & 0.154 & 0.024 & 35 & 0.019 & 0 \\
\hline 17 & 0.004 & 0 & 36 & 0 & 0 \\
\hline 18 & 0.102 & 0.262 & 37 & 0 & 0 \\
\hline 19 & 0.351 & 0.348 & 38 & 0.212 & 0.331 \\
\hline 20 & 0.020 & 0.028 & 39 & 0 & 0.012 \\
\hline 21 & 0.248 & 0.272 & 40 & 0.538 & 0.375 \\
\hline 22 & 0.034 & 0.175 & 41 & 0 & 0 \\
\hline
\end{tabular}

Description: ( $\mathrm{i}$ )the order of 42 universities is based on the list of first-class universities published by the Ministry of Education, and(ii) "_" indicates that this dimension does not enroll students.

\section{Results}

The total number of graduate enrollment disciplines in forty-two universities is 8541, with 2116 unequal disciplines, and 0.220 of the opportunity inequality index based on the dimension of degree type. It can be seen that, on the whole, the equal degree of entrance opportunities for postgraduate in 42 universities is relatively high. By analyzing the opportunity inequality index of forty-two universities (Table 1), it was found that eleven universities (accounting for $26.19 \%$ of the total number of universities) were completely equal in enrollment, and one $(2.38 \%)$ was completely unequal. The opportunity inequality index is divided into five intervals, $[0,0.2)$, $[0.2,0.3),[0.3,0.4),[0.4,0.5),[0.5,1]$, they represent very equal, relatively equal, relatively reasonable, relatively unequal, and very unequal(World Bank estimate, 2015), the number and proportion of universities in each intervals shown in Figure 1. This shows that most universities have a very high level of equal opportunity in postgraduate entrance, but there are still a considerable proportion of universities whose is very unequal. 


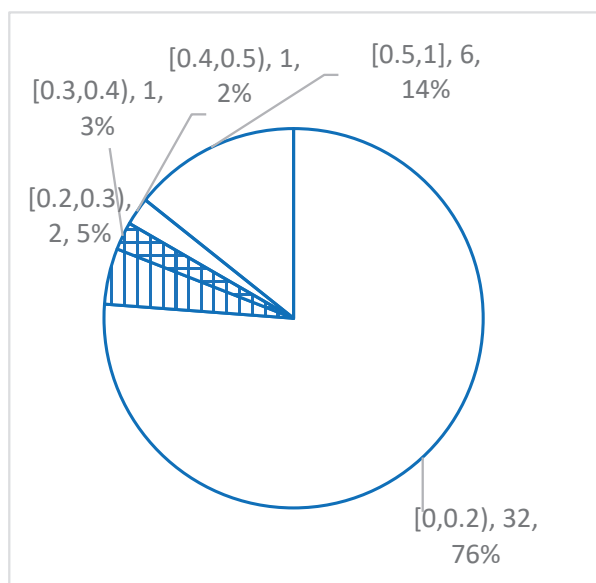

Figure 1. The Number and Proportion of Universities in Intervals

The proportion of unequal dicipline in academic degree is $23.49 \%$, and the opportunity inequality index is 0.208 , professional degree corresponding to $28.01 \%, 0.252$. There are 13 (accounting for $30.95 \%$ ) completely equal universities for postgraduate entrance in academic degrees, and four completely unequal universities, accounting for $9.52 \%$. In the professional degree, there are $18(42.86 \%)$ and $1(2.38 \%)$. According to the interval analysis of opportunity inequality index, both academic and professional degree show a generally consistent distribution (about $75 \%$ of universities have very high equality and $10 \%$ to $15 \%$ of universities are highly unequal). Hence, professional degree are more unequal than academic degree, but academic degree are more unequal in terms of the number of universities that are are completely equal and completely unequal, and the inequality in most universities is mainly caused by academic degree.

Attribution of unequal opportunity: The unequal contribution of bias is $16.65 \%$ in postgraduate enrollment, at the university level, there are 18 unequal universities what caused completely by the bias; the corresponding data of discrimination is $83.35 \%$ and 5(Figure 2). It can be seen that, on the whole, the inequality of 42 universities is mainly caused by discrimination, but at the university level, the influence of bias is more common.

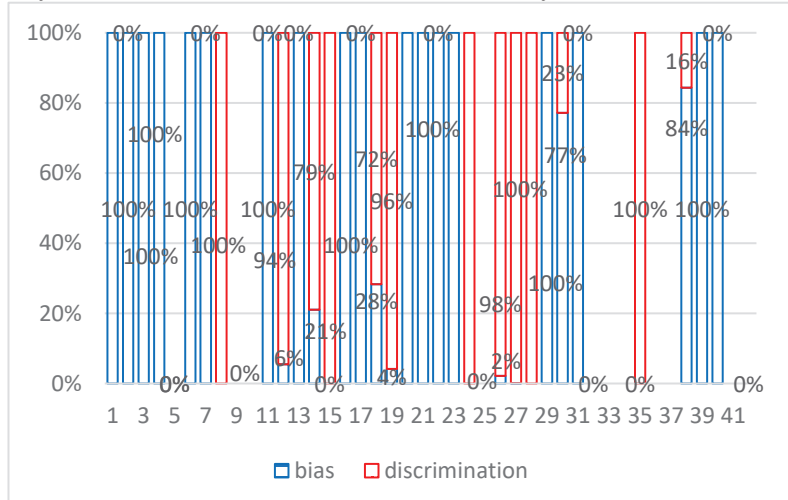

Figure 2. Unequal Contribution Eegree of Bias and Discrimination

The unequal contribution degree of bias is $17.20 \%$ in academic degrees, discrimination's is $82.80 \%$, the corresponding data of professional degree is $15.50 \%$ and $84.50 \%$; there are 16 equal universities what caused by the bias in academic degrees, discrimination's is 7, professional degree's is 13 and 4 . The unequal attribution of academic and professional degrees is consistent with the general observation that discrimination is the main reason for inequality of opportunity and that bias has a more widespread impact on inequality in universities.

The manifestation of unequal opportunities: the contribution of $\mathrm{N}_{4}$ (enrollment plan is only open to candidates who exempted from unified-examination), $\mathrm{N}_{5}$ (candidates are required to have a bachelor's degree) and $\mathrm{N}_{6}$ (the failure to accept those candidates, including equivalent students, college to undergraduate, and graduates from independent colleges or private colleges)were $6.15 \%, 10.50 \%$ and $83.35 \%$ respectively, academic degree (professional degree) were 6.74\% (4.91\%), 10.46\% (10.58\%), and 82.80\% (84.50\%), respectively. It can be seen that, on the whole, the main manifestations of inequality in 42 universities are $\mathrm{N}_{6}$, the influence of $\mathrm{N}_{5}$ is weak, and the influence of $\mathrm{N}_{4}$ is negligible; however, at the university level, the influence of unequal degree is decreased in turn $\mathrm{N}_{4}, \mathrm{~N}_{6}$ and $\mathrm{N}_{5}$.

\section{Suggestions}

On the whole, discrimination is the main reason for the inequality of opportunity in graduate enrollment: 
professional degree are more unequal than academic degree, but for the impact of overall inequality, academic degrees are greater than the former. Therefore, it is suggested that the discriminatory registration conditions in professional degree should be reduced, and academic degree enrollment requirements should be more open, so as to promote postgraduate entrance equality.

Nowadays, there are 2,631 colleges and universities in China, with only 369 universities having the qualification what have the candidates who exempted from unified-examination, therefore, it is suggested that the number of the qualified university should be increased. In addition, it is recommended that university should set up a reasonable enrollment plan in each disciplines, and ensure that all disciplines are open to all candidates, so as to reduce inequality in postgraduate enrollment.

\section{Acknowledgments}

I would like to thank the following two project funds: (1) CSADGE(Chinese Society Of Academic Degrees And Graduate Education) Key Project in 2017 (A1-2017Y0704-004) "Research on the equity of postgraduate education in China"; (2) MOE (Ministry of Education in China) Liberal arts and Social Sciences Foundation in 2017(17YJC880053) "Research on the quantitative analysis and governance system of postgraduate enrollment policy in China based on the theory of institutional change".

\section{References}

Babbie E R. The practice of social research [M]. Thomson Wadsworth, 2007: 170.

General office of the ministry of education of the People's Republic of China. Notice of the General Office of the Ministry of Education on Further Strengthening the Recommendation of Excellent Fresh Graduates to Take Postgraduates [Z]. 2013.09.04

Gini C. Variabilità e mutabilità [J]. Reprinted in Memorie di metodologica statistica (Ed. Pizetti E, Salvemini, T). Rome: Libreria Eredi Virgilio Veschi, 1912.

Nagel T. Equality and partiality [M]. Oxford University Press, 1995: 44-70,

Rawls J R. A Theory of Justice (1971) [M]. Harvard university press, 1999: 13, 53-72, 266.

Rawls J R. Justice as Fairness [M]. Yao Dazhi Translation. China Social Sciences Press, 2001: 56,137-139.

Sen A. Equality Reexamined [M]. Wang Liwen, Yu Zhanjie Translation. China Renmin University Press, 2016: 22-23.

Sen A. Poverty: an ordinal approach to measurement [J]. Econometrica: Journal of the Econometric Society, 1976: 219-231.

The Chinese Academic Degree Committee of State Council, the Ministry of Education of the People's Republic of China (MOE). Notice on Printing and Distributing "the Regulations on the Establishment and Management of Academic Degree and Talent Cultivation Disciplines” [Z]. 2009.02.25

The Ministry of Education of the People's Republic of China (MOE). Notice of the Ministry of Education on Printing and Distributing the "Regulations on the Management of National Postgraduate Enrollment in 2018” [EB/OL]. http://www.moe.edu.cn/srcsite/A15/moe_778/s3261/201708/t20170831_312801.html, 2017-08-29

The Ministry of Education of the People's Republic of China (MOE). Notice of the Ministry of Education on Printing and Distributing "The National Colleges and Universities Recommended Outstanding Fresh Graduates to Study Master's Degree in Management Methods of Postgraduate Work" [Z]. 2006.07.12
The World
Bank.
GINI
index
(World
Bank
estimate)

[EB/OL].https://data.worldbank.org/indicator/SI.POV.GINI/?type=shaded\&view=map, 1979-2015.

Wang Haiming. New Ethics [M]. The Commercial Press, 2001: 879-914,

Iwas born Jining city in china 1990. I completed my First Degree in ProjectManagement at Qingdao Technological University in QingdaoShandong China 2013, before joined for my DoctorateDegreeatUniversity of Science and Technology of Chinain Hefei Anhui Province.Now my major is public administration, and my research direction is education policy, at University of Science and Technology of China. 